University of Nebraska - Lincoln

DigitalCommons@University of Nebraska - Lincoln

January 2005

\title{
Complex signal function: Developing a framework of testable hypotheses
}

\author{
Eileen Hebets \\ University of Nebraska - Lincoln, ehebets2@unl.edu \\ Daniel R. Papaj \\ Department of Ecology and Evolutionary Biology, University of Arizona, Tucson, AZ
}

Follow this and additional works at: https://digitalcommons.unl.edu/bioscihebets

Part of the Behavior and Ethology Commons

Hebets, Eileen and Papaj, Daniel R., "Complex signal function: Developing a framework of testable hypotheses" (2005). Eileen Hebets Publications. 22.

https://digitalcommons.unl.edu/bioscihebets/22

This Article is brought to you for free and open access by the Papers in the Biological Sciences at DigitalCommons@University of Nebraska - Lincoln. It has been accepted for inclusion in Eileen Hebets Publications by an authorized administrator of DigitalCommons@University of Nebraska - Lincoln. 
Published in Behavioral Ecology and Sociobiology 57:3 (January 2005), pp. 197-214; doi 10.1007/s00265-004-0865-7

Copyright (C 2004 Springer-Verlag. Used by permission. http://www.springer.com/life+sci/behavioural/journal/265

Submitted January 16, 2004; revised October 8, 2004; accepted October 13, 2004; published online November 11, 2004. Communicated for BES by A. Cockburn.

Review

Complex signal function: Developing a framework of testable hypotheses

\author{
Eileen A. Hebets* and Daniel R. Papaj ${ }^{\dagger}$ \\ * Division of Insect Biology, Department of Environmental Science, Policy and Management, University of California, \\ Berkeley, CA 94720, USA (Corresponding author) \\ ${ }^{\dagger}$ Department of Ecology and Evolutionary Biology, University of Arizona, Tucson, AZ 85721, USA
}

\begin{abstract}
The basic building blocks of communication are signals, assembled in various sequences and combinations, and used in virtually all inter- and intra-specific interactions. While signal evolution has long been a focus of study, there has been a recent resurgence of interest and research in the complexity of animal displays. Much past research on signal evolution has focused on sensory specialists, or on single signals in isolation, but many animal displays involve complex signaling, or the combination of more than one signal or related component, often serially and overlapping, frequently across multiple sensory modalities. Here, we build a framework of functional hypotheses of complex signal evolution based on content-driven (ultimate) and efficacy-driven (proximate) selection pressures (sensu Guilford and Dawkins 1991). We point out key predictions for various hypotheses and discuss different approaches to uncovering complex signal function. We also differentiate a category of hypotheses based on inter-signal interactions. Throughout our review, we hope to make three points: (1) a complex signal is a functional unit upon which selection can act, (2) both content and efficacy-driven selection pressures must be considered when studying the evolution of complex signaling, and (3) individual signals or components do not necessarily contribute to complex signal function independently, but may interact in a functional way.
\end{abstract}

Keywords: multimodal signal, multicomponent signal, communication, signal design, signal interactions

\section{Introduction}

Animal signals have received a great deal of attention from scientists across many disciplines, including psychology, neurobiology, ethology, behavioral ecology and evolutionary biology. While this attention has gener- ated a large body of information relating to signal design and evolution, much of the previous research has examined individual signals in isolation and has often focused on sensory specialists (animals that rely predominantly on one sensory modality) [e.g., vision: (Andersson 1982; Bischoff et al. 1985; Basolo 1990; Petrie et al. 1991; Brooks and Caithness 1995; Ligon and Zwartjes 1995); acoustics: (Wells 1977; Ryan 1980; Ryan 1985; Bailey et al. 1990; Ryan and Rand 1990; Gerhardt 1991)]. As we understand more about communication in various systems, we are increasingly confronted with the fact that signaling generally involves complex behavioral routines, incorporating more than one signal or related component, often serially and overlapping, frequently across multiple sensory modalities (Hughes 1996; Borgia and Presgraves 1998; Møller and Thornhill 1998; Hebets and Uetz 1999; Hölldobler 1999; Partan and Marler 1999; Rowe 1999; Rowe and Guilford 1999a; Rowe and Guilford 1999b; Rowe 2002; Uetz and Roberts 2002). While an interest in complex signaling within certain taxonomic groups has been present for some time (see Halliday and Slater 1983), and while many of the ideas in this review are not new, advances in technology in conjunction with an increased understanding of peripheral sensory systems and neural processing has resulted in a recent increase of studies on complex signal function (for review see Candolin 2003). Enhancement of both technology and knowledge base has also led to new functional hypotheses of complex signaling. However, despite the escalation in interest and ideas, there is currently no general framework uniting these studies. Here, we attempt to bring together several functional hypotheses of complex signaling with the goal of providing a framework within which future, as well as past, investigations 
can be placed. This framework is based upon operational definitions and upon empirical approaches to studying complex signal function. We begin our discussion by defining the relevant terms.

\section{Definitions}

The basic building blocks of communication are signals. While many, subtly varying definitions of the term "signal" have been proposed, our definition is based partly on Markl's definition of communication (1983 modified from Wilson 1975):

A signal is a packet of energy or matter generated by a display or action of one organism (the signaler) that is selected for its effects in influencing the probability pattern of behavior of another organism (the receiver) via its sensory-nervous system in a fashion that is adaptive either to one or both parties.

This definition embraces two themes common to most definitions of the term: (1) a signal conveys information in the form of energy or matter and (2) a signal elicits a behavioral response in the receiver (Markl 1983; Zahavi 1987; Wiley 1994; Hauser 1996; Bradbury and Vehrencamp 1998). While signals do not always result in overt behavioral responses by receivers, they are most easily studied by assessing their effects on the behavior of the receiver (Hasson 1994; Maynard Smith and Harper 1995; Hasson 1997). Since our focus here is on operational definitions and testable hypotheses, we restrict the term signal to instances where there is an observable change in the behavior of the receiver. Regarding the first theme, perspectives vary as to whether the information need be of positive value to the receiver. We adopt the position that information conveyed by a signal need not be useful to the receiver and can even sometimes lead to behavior that diminishes the receiver's performance.

Throughout this review, we use the term "complex signaling" as an umbrella under which the terms "multicomponent signals," "multiple traits," "multiple signal," and "multimodal signal" reside. While it is useful to initially approach a new system in as general a way as possible, as more knowledge is acquired, more detailed descriptions may be useful and thus, we will briefly discuss three categories of complex signaling below.

Complex displays are frequently made up of multiple components (multicomponent signals), none of which elicit a receiver response on their own. However, multiple components may interact with each other or with other signals to alter a receiver's response (Hasson 1989; Guilford and Dawkins 1991), and thus comprise a complex display. While a component may not elicit a receiver response on its own, it need not be uninformative as components may be cues that reflect signaler quality, yet have not been shaped by selection for communication (see Candolin 2003). Multicomponent signals generally refer to complex displays in which all of the compo- nents are perceived within one sensory modality (Rowe 1999).

Multiple signals refer to instances where each signal can elicit a behavioral response on its own. The capacity for individual signals to elicit responses does not, however, imply that the signals are necessarily non-interacting. Male coqui frogs, Eleutherodactylus coqui, provide an example of multiple signaling. Male coqui frogs produce a "compound advertisement call" consisting of a "co" note and a "qui" note. Using playbacks, Narins and Capranica (1976) demonstrated that in isolation, the "qui" \{ note attracted females while the "co" did not. In contrast, males responded to the "co" note, but not to the "qui" note (Narins and Capranica 1976). In this example, while each signal in isolation elicits a receiver response, the signals appear to convey different information to different receivers ("multiple messages"-“receiver variability" hypotheses below). These signals together comprise a unimodal (only one sensory modality) multiple signal.

Multimodal signals are another distinct category of complex signals distinguished by being composed of more than one signal in more than one sensory modality (Scheffer et al. 1996; Hebets and Uetz 1999; Partan and Marler 1999; Rowe 1999; Hebets 2004). Aposematic, or warning, displays provide some of the best and most widespread examples of multimodal signaling (for review see Rowe and Guilford 2001). Most aposematically colored insects emit odors or sounds in addition to their colorful patterning when they are approached or attacked by predators (Cott 1940; Rothschild 1961; Rothschild and Haskel 1966; Edmunds 1974; Rowe and Guilford 2001). The use of warning colors is thought to decrease the probability of predator attack and/or enhance the predator's avoidance learning that occurs after an attack (for review see Schuler and Roper 1992). Many recent studies have examined how both odor and sound interact with warning coloration to potentially increase predator aversion (Marples et al. 1994; Marples and Roper 1996; Rowe and Guilford 1996; Roper and Marples 1997; Rowe and Guilford 1999b; Rowe 2002).

Courtship signaling is another context in which many examples of multimodal signaling exist. For example, within the wolf spider genus Schizcosoa males of many species simultaneously produce both visual and vibratory courtship signals (McClintock and Uetz 1996; Scheffer et al. 1996; Hebets and Uetz 1999; Hebets 2002; Uetz and Roberts 2002; Hebets 2004). Members of this genus are especially intriguing since closely related species signal unimodally versus multimodally (Hebets and Uetz 1999; Hebets 2002; Uetz and Roberts 2002). While specific hypotheses of complex signal function are beginning to be tested directly in this system (Hebets 2004), over the past 10 years, researchers have attempted to elucidate the role of each signal in female choice across multiple species by assessing female receptivity to isolated courtship components (Table 1). Preliminary studies suggest that the signal functions may vary across closely related species. 
Table 1. A summary of results from prior research examining female receptivity to isolated courtship signals of conspecific males across six species of Schizocosa wolf spiders. The "courtship" column indicates whether the male's natural courtship display includes a vibratory signal only ("unimodal') or a vibratory signal plus a visual signal ("bimodal"). The values in the columns labeled "visual," "vibration," and "visual + vibration" are the proportion of females that were receptive to male courtship displays involving only a visual signal (visual), only a vibratory signal (vibratory) or the full courtship display (visual + vibration).

\begin{tabular}{|c|c|c|c|c|c|c|}
\hline Species & $\begin{array}{l}\text { Male Foreleg } \\
\text { Morphology }\end{array}$ & Courtship & Visual & Vibration & $\begin{array}{l}\text { Visual + } \\
\text { Vibration }\end{array}$ & Source \\
\hline S. rovneri & & Unimodal & 37 & .79 & 89 & $\begin{array}{c}\text { Scheffer et al., } \\
1996\end{array}$ \\
\hline S. duplex & & Unimodal & 0 & 89 & 89 & $\begin{array}{c}\text { Hebets \& Uetz, } \\
1999\end{array}$ \\
\hline S. uetzi & & Bimodal & .25 & .71 & .5 & $\begin{array}{c}\text { Hebets \& Uetz, } \\
1999\end{array}$ \\
\hline S. stridulans & & Bimodal & .5 & 63 & 63 & $\begin{array}{l}\text { Hebets \& Uetz, } \\
1999\end{array}$ \\
\hline S. crassipes & & Bimodal & 5 & 5 & .75 & $\begin{array}{c}\text { Hebets \& Uetz, } \\
1999\end{array}$ \\
\hline S. ocreata & & Bimodal & .64 & 69 & .93 & $\begin{array}{c}\text { Scheffer et al., } \\
1996\end{array}$ \\
\hline
\end{tabular}

Table 2. Content-based hypotheses - function relates to the content or message(s) conveyed in a complex display

\begin{tabular}{ll}
\hline I. Multiple messages & $\begin{array}{l}\text { Different signals provide different information: either different types of information or information about differ- } \\
\text { ent aspects of signaler quality }\end{array}$ \\
& (1) Quality: both signals convey different aspects of signaler quality; referred to in the literature as "multiple mes- \\
& sages" \\
& (1a) Static versus dynamic: one signal conveys more static properties (i.e. genetic indicators) while a second con- \\
& veys more dynamic properties (i.e., current condition) \\
& (2) Species recognition: one signal conveys species identity while another conveys a different type of information \\
& such as signaler quality \\
& (3) Quality plus: one signal conveys signaler quality while another provides a different type of information such \\
as signaler location & (4) Receiver variability: different signals are directed at different receivers due to variable receiver preferences \\
II. Redundant signal & Different signals provide the same information, allowing for increased accuracy of receiver response
\end{tabular}

The frequency and diversity of complex displays in general and multimodal signals in particular throughout animal displays is striking and may suggest a particular advantage to incorporating signals in multiple sensory modalities irrespective of the ultimate purpose of the display. In an informal survey of nature guides describing bird displays, we found that $92 \%$ of the 73 species examined possessed at least one multimodal display within their behavioral repertoire, with the majority possessing two or more (Stokes 1979; Stokes and Stokes 1983; Stokes and Stokes 1998) (Fig. 1). While this summary includes displays in contexts other than courtship, it only includes audiovisual displays. Many studies of multimodal signaling focus on systems with obvious audiovisual displays (Uetz and Roberts 2002; Cooper and Goller 2004; Rosenthal et al. 2004; Hebets 2004), probably due to the ease with they are identifiable. However, more examples of multimodal interactions involving olfaction are being revealed (Jetz et al. 2001; Lindstrom et al. 2001; Rowe and Guilford 2001; Acquistapace et al. 2002) and it is likely that there are many more yet to be discovered. We sus- pect that olfactory interactions will comprise a large proportion of future examples of multimodal signals. We also suspect that as more surveys such as this are conducted, displays confined to a single sensory modality may prove to be the exception rather than the rule.

\section{Selection pressure acting on complex signaling}

In order for a signal to be successful, whether complex or not, it must not only convey the appropriate information, but must also be sent successfully through the environment and be received and processed in such a way as to elicit the appropriate receiver response. Guilford and Dawkins (1991) distinguish two kinds of selection pressures acting on signals, referring to them as content-based and efficacy-based selection. Content-based selection relates to factors affecting the message or information content of the signal (i.e., the "why" of the signal), whereas efficacy-based selection relates to how well the signal propagates through the environment and how effectively it is received and processed (i.e., the "how" of the signal). 
Figure 1. A survey of 73 bird species compiled from Stokes Nature Guide's. By counting the number of displays per species that were described as having components in more than one sensory modality, we found that $92 \%$ of species surveyed had at least one multimodal display.

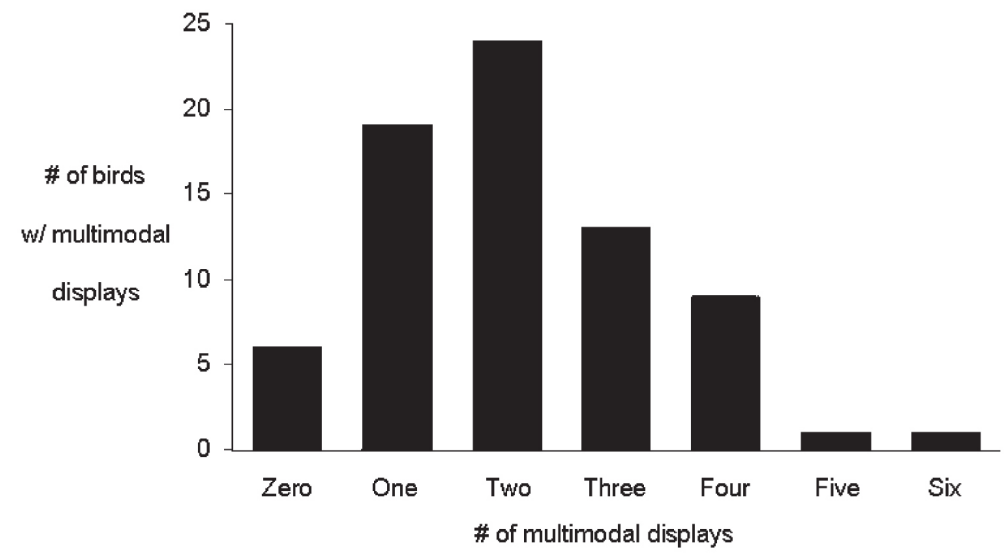

Table 3. Efficacy-based hypotheses - function relates to the efficacy with which a signal(s) travels through the environment and is received and/or processed by a receiver

\begin{tabular}{ll}
\hline I. Multiple & Signal transmission and reception is influenced by environmental conditions \\
sensory & (1) Efficacy backup: each signal acts as a backup to the other in the presence of environmental variability \\
environments & (2) Efficacy trade-off: the transmission characteristics of each signal vary; each one is specialized to overcome a partic- \\
ular transmission impediment & The receiver's sensory system influences the detection and processing of signals \\
II. Sensory & (1) Parallel processing: multiple bits of information can be processed simultaneously, potentially reducing the latency \\
to receiver response & \\
(2) Sensory bias for multisensory integration: given the existence of multisensory neurons, a multimodal signal en- \\
hances the neuronal response, thereby increasing the salience of the event \\
(3) Sensory overload: a signaler can "jam" a receiver's reception and/or processing system by providing more infor- \\
mation than can be handled by the receiver's sensory system \\
(4) Perceptual variability: each signal acts as a backup to the other in the presence of perceptual variability among \\
receivers
\end{tabular}

Table 4. Inter-signal interaction hypotheses - function incorporates signal interactions in which one signal alters either the production of a second signal, or a receiver's response to a second signal
I. Multitasking
II. Increased detection and discrimination
A signaler's ability to generate one signal is constrained by, and thus negatively correlated with, his/her abil- ity to generate another signal
The presence of one signal either increases the probability and/or speed of detection of a second signal, or increases the accuracy with which a receiver responds to a second signal
(1) Amplifier: one signal increases the probability of detection of the second signal and/or decreases the de- tection threshold, making it more conspicuous
(2) Alerting and attention-altering: one signal either alerts a receiver to a second signal, thereby decreasing the reaction time, or influences the information filtering mechanism of the receiver such that the receiver's attention is focused on another signal
(3) Context: the presence of one signal provides a context in which a receiver can interpret and respond to a second signal
(4) Emergence: a receiver is better able to discriminate among signalers due to the emergent properties of combining multiple signals in such a way that a new, unique signal is formed
III. Increased learning and memory
The presence of one signal increases a receiver's ability to learn and/or remember another signal or the en- tire display
IV. Increased deception
The presence of one signal decreases the accuracy with which a receiver responds to another signal

Although the distinction between these two "design components" is not always clear-cut, it can help us to organize our thinking about the function of complex signaling. We additionally consider selection acting on interactions between signals. Such interactions can be thought of as resulting mostly from content-based selection pressure, efficacy-based selection pressure, or a combination of both. In short, we consider three categories of hypotheses for the function of complex signaling: content- based hypoth- eses, efficacy-based hypotheses, and inter-signal interaction hypotheses (Tables 2, 3, 4). While examples in our review include agonistic displays and warning displays, for simplicity, our predictions are stated specifically with reference to courtship displays.

\section{Content-based hypotheses}

In many, if not most cases, the ultimate function of a communication routine is known. For example, court- 
ship displays function to procure a copulation; warning displays function to prevent a predator's attack; begging displays function to solicit feeding behavior from one's parents; agonistic displays function to ward off potential rivals; and so on. In each case, the displays inform, they have content. In order for a courtship display to be successful, for example, the suitor generally provides a receiver with information about his/her identity as a conspecific as well as information about his/her quality as a mate or parent. Similarly, before an intruder decides to retreat from a rival's territory, it assesses its opponent's strength, as conveyed by the opponent's agonistic display. In this section, we discuss how complex signaling may be designed to maximize content to the advantage of the signaler and/or receiver. We recognize two distinct categories of content-based hypotheses for complex signals, termed "multiple messages" and "redundant signal" hypotheses (Table 2).

Under all content-based hypotheses, to the extent that more information is better information, receivers should benefit from assessing an entire complex display as compared to assessing individual parts in isolation.

\section{Multiple messages}

The term multiple messages is used at present more narrowly than we use it here (Møller and Pomiankowski 1993; Johnstone 1996). Instead of referring only to information regarding different aspects of signaler quality, as for example in mate choice (Møller and Pomiankowski 1993; Johnstone 1996), we would like to expand the category to include any instance involving the transfer of more than one type of information. Under these hypotheses, since each signal conveys different information, we would not predict the signals to have a tight covariance and in many cases, we would also not predict the signals to covary with signaler quality (Candolin 2003).

Within this general category of multiple messages, we outline four hypotheses found in the literature, relating to specific types of information conveyed: (1) a "quality" hypothesis states that different signals reflect different aspects of a signaler's quality (Møller and Pomiankowski 1993; Johnstone 1996), (2) a "species recognition" hypothesis states that one signal reflects species identity while another indicates another type of information such as signaler quality, (3) a "quality plus" hypothesis states that one signal indicates signaler quality while another provides a different type of information such as signaler location, and (4) a "receiver variability" hypothesis states that different signals are directed at different receivers due to variable receiver preferences.

1. Quality: A quality hypothesis of multiple messages proposes that each signal reflects a different aspect of a signaler's quality. For example, a complex courtship display may convey multiple bits of information relating to parasite resistance, body size, foraging ability, parenting ability or quality of a defended resource. McGraw and Hill (2000) provide an excel- lent example with respect to the American goldfinch, Carduelis tristis, where they found that the black cap of the bird provides information about social interactions while the plumage and bill coloration are potential indicators of intestinal infection (McGraw and Hill 2000). In black-billed magpies, Pica pica, Blanco and De la Puente (2002) showed that different aspects of individual quality are correlated with tail features, again potentially providing receivers with multiple pieces of information about individual quality (Blanco and De la Puente 2002). In a study of satin bowerbirds, Ptilonorhynchus violaceus, Doucet and Montgomerie (2003) found that a male's ultraviolet plumage coloration conveys information about his feather growth rate, body size, and level of blood parasite infection. Independently, the quality of the bower structure that the male builds conveys information about ectoparasite load and body size (Doucet and Montgomerie 2003).

1a. Static versus dynamic: Signals may be selected for their function in relating condition over vastly different time scales, where an animal conveys both static or relatively fixed information as well as dynamically changing information about internal state, intent, or quality (Candolin 2003). In the field cricket Gryllus campestris, nymphal nutritional treatment has been shown to influence the carrier frequency of male calls, with food-restricted males calling at a higher carrier frequency (Scheuber et al. 2003b). This nutritional treatment did not influence chirp rate or chirp intensity and prior work established chirp rate to be a good indicator of current condition (Scheuber et al. 2003a). Thus, carrier frequency in the field cricket potentially provides information about the signaler's past condition while chirp rates provide information about the signaler's current condition.

Plumage coloration in birds provides another classic example of a multiple messages function relating to both static and dynamic quality information. Carotenoidbased plumage coloration is highly dependent on diet, as animals are not known to be able to synthesize carotenoid compounds (Fox 1976; reviewed in Badyaev and Hill 2000). Melanin-based plumage coloration, by contrast, is synthesized as a by-product of amino-acid catabolism and is thus under genetic control and not influenced by physical condition (Fox 1976; reviewed in Badyaev and Hill 2000). Thus, the reds, oranges, and yellow color patches of birds likely reflect current condition or dynamic properties while the black, greys and browns likely provide more static, genetically based information (see references in Badyaev and Hill 2000). In a recent review of multiple cues in mate choice, Candolin (2003) provides additional examples of multiple messages consistent with the quality hypothesis. An ideal test of this hypothesis of multiple message function would involve a known manipulation of signaler quality while tracking signal variation. 
2. Species recognition: A species recognition hypothesis states that one signal in a complex display provides species identity information while another provides another type of information such as signaler quality. The evolution of multiple traits has been argued to result from an ongoing interplay between species and mate-quality recognition (Pfennig 1998). In swordtail fish, size cues and ornamentation apparently mediate mate-quality assessment and species recognition respectively. Females of the pygmy swordtail fish, $\mathrm{Xi}$ phophorus pygmaeus, use the presence of bars for species identification while using body size as an indication of conspecific male quality (Hankison and Morris 2002). In anurans, by comparing signal parameters for calls of conspecific and heterospecific frogs, Gerhardt (1991) found that some signal parameters remained constant, presumably for species identification, while others varied within and between individuals, presumably providing information about individual quality. Further evidence in insects and anurans suggests that certain properties of acoustic signals (i.e., pulse rate) function in species identification (Ewing 1989; Bailey 1991; Gerhardt 1991) while other more dynamic properties indicate male quality (Gerhardt and Huber 2002). In short, the complex acoustic signals of some insects and anurans consisting of variation in carrier frequency, pulse rate, and call length and rate may be the result of selection for both species recognition and signaler quality.

Selection for multiple messages conveying both species recognition and signaler quality may also account for certain multimodal displays. For example, in choice tests with the swordtail fish X. pygmaeus, females preferred heterospecific males over conspecifics in visual-only trials (Ryan and Wagner 1987) but no longer preferred heterospecifics when presented both with a visual and a chemical signal (Decaprona and Ryan 1990). In this example, it is likely that the chemical signal mediates species recognition, while the visual signal mediates conspecific assessment. A similar example of multiple messages involves the acoustic courtship display of male ctenid spiders. The courtship display of Cupiennius salei consists of acoustic signals generated by two different body parts: the opisthosoma and the pedipalps. While the opisthosomal signal appears to convey species identity information, the pedipalpal signal appears to convey information about location (Baurecht and Barth 1992). In this last example, species recognition is grouped with a signal conveying another type of information, location, instead of a quality indicator.

3. Quality plus: A quality plus hypothesis of multiple message function states that one signal indicates signaler quality while another indicates a different type of information such as signaler location or territory quality. An excellent example of this is provided by Candolin and Reynolds (2001) in their work on the freshwater fish, the European bitterling, Rhodeus seri- ceus. Females first inspect males based on their behavior and their red coloration and are more attracted to bright males that court vigorously. It is suggested that the red carotenoid-based coloration of the males may reflect nutritional condition and thus male quality (Candolin and Reynolds 2001). However, males display on and defend a freshwater mussel in which females ultimately spawn. Offspring survival has been shown to depend both on mussel species and on the density of embryos already present (Smith et al. 2000) and thus, it is important for females to assess mussel quality as well as male quality. Candolin and Reynolds (2001) were able to show that females based their initial approach on male behavior and coloration and based their spawning decision on mussel quality, acquiring information both about male quality and quality of spawning location.

4. Receiver variability: A receiver variability hypothesis of multiple messages states that different signals are directed at different receivers due to variable receiver preferences. This hypothesis encompasses situations where a complex signal may function to convey information intended for two different receivers, sometimes simultaneously. A common example of multiple receivers involves male displays in which one component is important in male-male competition, while another is important in female choice (Savalli 1994; Grether 1996). We should expect complex signaling in the context of multiple receivers when the different receivers require different kinds of information. For instance, if body size information were being conveyed to both male and female receivers, a single signal might suffice. However, if body size was relevant to males but parasite load to females, then some combination of components or signals might be required.

Since a signaler can typically distinguish between a male versus female receiver, and since it may not be common for both receivers to be present simultaneously, the above argument for complex signal function may not always fit a definition of complex signaling. However, if a signaler cannot distinguish between receivers, a complex display may be beneficial. Receiver variability within a given category (e.g., variability among females) is recently gaining more attention by scientists, especially with respect to mating preferences, as more studies are suggesting that females differ in what traits they use to choose their mates. For example, Coleman et al. (2004) recently demonstrated that female satin bowerbirds, $P$. violaceus, of different ages use different male display traits to make decisions (Coleman et al. 2004). Given that males can mate with multiple females, and given that females may vary in their mate-choice preferences, a complex signal can serve to simultaneously address any age or stagespecific preferences females may have. Genotype-dependent mate preferences, where females choose mates in an attempt to compliment their own genetic make-up, 
are also suggested to be widespread (for review see Tregenza and Wedell 2000). In these instances, again, females are expected to have variable mating preferences, which could be manifest in preferences for different male traits. In both of these instances, males may not have a priori knowledge of what individual female's preferences are, resulting in the potential usefulness of a complex display.

Multiple messages summary We have outlined four possible types of multiple messages, but others may exist. For example, the food-begging display by nestling birds likely fits into a type of multiple messages hypothesis not found in this outline. Nestlings typically combine both visual and acoustic signals in soliciting food from their parents. The resulting display influences both the parents' foraging effort and the offspring's access to delivered food. A recent study (Glassey and Forbes 2002) demonstrated that each signal is responsible for one of these effects: the acoustic signal regulates the rate at which parents forage while the visual signal regulates access to food. This example does not fit neatly into any of the subcategories we have presented. It is likely that more types will be found, as more systems are explored.

\section{Redundant signal}

A redundant signal hypothesis (Møller and Pomiankowski 1993), or "backup signal" hypothesis as termed by Johnstone (1996), states that different signals provide the same information and allow for an increased accuracy of receiver response. Whether in a mate-choice situation or a potential agonistic encounter, it is often useful to ascertain as complete as possible an estimation of the overall quality of a signaler. The redundant signal hypothesis relies on the premise that signalers are imperfect in their coding, or in the accuracy, or lack of accuracy, with which they encode information (Bradbury and Vehrencamp 1998). The generation of any given signal may encode one or more condition(s) of a signaler, however, the coding for any one signal given the pertinent condition is often less than perfect (i.e., the probability that signal $S_{\mathrm{j}}$ will be produced when condition $C_{\mathrm{i}}$ is true is less than one: $P\left(S_{\mathrm{j}} \mid C_{\mathrm{i}}\right)<1$, sensu (Bradbury and Vehrencamp 1998). In the face of imperfect coding, the total amount of information sent by a signaler may be increased by combining multiple signals, which independently encode the same or similar information (see Bradbury and Vehrencamp 1998). The notion of imperfect sender coding implies some kind of constraint on the capacity of any one signal to convey information perfectly accurately. Under the redundant signal hypothesis, all signals are predicted to have a tight covariance and should covary with signaler quality. While correlation certainly does not imply causation, currently correlative data are useful in first exploring potential content-based hypotheses.

Results in a small number of recent studies are suggestive of a redundant signal function of complex signaling. For example, in northern cardinals, Cardinalis cardina- lis, body size and body condition show high correlations with both the red-orange bill color of females as well as the redness of the feathers under their wings, suggesting that both signals convey the same information (Jawor et al. 2004). The female's face mask pattern, however, is correlated with the level of intrasexual aggression as well as nestling feeding rate, suggesting that both the redundant signal and multiple messages hypotheses account for the multiple ornaments of female northern cardinals (Jawor et al. 2004). The courtship signals in zebra finches may also constitute an example of redundant signaling due to imperfect coding. Both beak color and song rate of zebra finches appear to provide the same information about the signaler. Males that have either redder beaks or higher song rates seem to be in better condition, and thus represent higher quality mates (Birkhead et al. 1998). Presumably, a receiver that is allowed to assess both beak color and song rate gains more precise information about overall signaler quality than would a receiver that assessed only one or the other signal. Similarly in curassow, knob height, wattle height, and wattle width are all partially independent indicators of male age; a trait used by females to make mating decisions (Buchholz 1991). Taken together, these cues may provide a better estimate of male age than any one in isolation.

Multiple colors involved in signaling displays can often represent different carotenoid components, each independently conveying information about an individual's foraging ability (Wedekind et al. 1998; Grether et al. 1999). Two groups of carotenoids found in fish, astaxanthin and tunaxanthin/lutein, contribute to red and yellow colors, respectively (Wedekind et al. 1998). Females choosing males based on this complex signal may gain more precise information about foraging ability than a single signal would permit (Wedekind et al. 1998). In this example, a multiple messages hypothesis may conceivably be more appropriate. If a receiver evaluates the specific foraging abilities of signalers based upon the different carotenoids, then we would interpret this foraging example as a multiple messages example of quality, with different carotenoids providing different information about different aspects of foraging.

Redundant signaling may also prevent signalers from cheating, allowing a receiver to accurately assess a signaler even when presented with contradictory evidence. For example, one component of a complex signal may be more easily exaggerated than another and thus an assessment of multiple signals may provide a more accurate assessment of over-all signaler quality. In a classic study, Zuk et al. (1993) manipulated the color and/or length of male red jungle fowl combs (Gallus gallus) and conducted female mate-choice trials. Females were shown to ignore the manipulated characters and rely instead on secondary sexual characters that had previously been of secondary importance. The authors suggest that when presented with contradictory evidence, females ignore the anomalous character and rely on other traits. 
Efficacy-based hypotheses

Whereas content-based hypotheses of complex signal function focus solely on the message(s) conveyed by a complex signal, efficacy-based hypotheses address factors that influence the production, transmission, reception, and processing of complex signaling, such as the environment through which signals travel or the sensory system of the intended receiver (Table 3 ). In contrast to content-based hypotheses, pure efficacy-based hypotheses of complex signal function are frequently more amenable to empirical tests and experimental manipulations.

\section{Multiple sensory environments}

Candolin (2003) introduced the term "multiple sensory environment" to address situations where signal transmission and reception is influenced by environmental conditions. We outline two hypotheses within this category in which the environment through which a signal(s) travels influences signal function: (1) an "efficacy backup" hypothesis states that multiple signals act to back each other up in the presence of environmental variability, and (2) an "efficacy trade-off" hypothesis states that the transmission characteristics of each signal are designed to overcome a particular transmission impediment. Under both hypotheses, the main prediction is that receiver response will vary across environmental conditions.

1. Efficacy backup: An efficacy backup hypothesis states that each signal acts as a backup to the other in the presence of environmental noise. Under this hypothesis, each signal is sufficient to elicit the desired receiver response, and across all environmental conditions, the probability of receiver response should be greatest when both signals are present compared to when either signal is in isolation: across all environmental situations, the probability of response $(r)$ to the complex signal $(a, b)>r(a)$ or $r(b)$. Since each signal conveys the same information under this hypothesis, the signals should have a tight covariance.

Animal signals must be detected against a background of environmental noise and, as such, many signaling systems appear to be adapted to cope with noise. Variation in the nature of environmental noise, however, poses a special challenge for signal efficacy. A multitude of factors such as light level, humidity, wind speed and direction, background levels of noise resulting from communication by competitors, and physical obstacles vary both temporally and spatially. In some cases, animals do not require complex signaling to cope with such variation. For instance, some animals signal only at a particular time of day, under particular environmental conditions, or from specific locations. The tawny owl, Strix aluco, for example, tends to call mostly in dry conditions resulting in an almost 70-fold advantage in calling range compared to when calling in rainy conditions (Lengagne and Slater 2002). In windy conditions, many birds increase the number of calls emitted as well as the number of sylla- bles per call (Lengagne et al. 1999). In response to various levels of white noise, zebra finches, Taeniopygia guttata, increase their amplitude levels (Cynx et al. 1998). By calling at night, the bladder grasshopper, Bullacris membracioides, increases its acoustical transmission range by $1.5-1.9 \mathrm{~km}$ (Van Staaden and Romer 1997).

While animals can increase their signal range, or increase their signal to noise ratio by changing their behavioral patterns, or by altering the signal itself, such strategies can be constraining and/or difficult. The use of multiple signals, in which the same information is sent using more than one signal with differing transmission properties, might be an alternative means of coping with spatial and temporal variability. In essence, one signal backs up the other signal in the face of unpredictable variation in environmental noise. As such, redundancy in the information conveyed in complex signals need not necessarily reflect the effects of content-based selection, but can instead result from efficacy-based selection.

Key to this hypothesis is variability in the pattern of environmental stimuli affecting transmission and reception of signals. For instance, Endler (1992) discusses different ways in which the conspicuousness of a color pattern can be maximized under different environmental conditions. Individuals courting in shaded forests are most conspicuous if they display with red and orange pigments, while individuals courting in shaded woodlands are most conspicuous if they display with blue or blue-green pigments (Endler 1992). In a study of lekking birds in French Guiana, three different species (Rupicola rupicola, Corapipo gutturalis, and Lepidothrix serena) were shown to display under light conditions that maximized their conspicuousness (Endler and Thery 1996). Similarly, different populations of an anolis lizard, Anolis cristatellus, were shown to have differences in their dewlap design related to differences in signal detectibility in mesic versus xeric environments (Leal and Fleishman 2004). In the above examples, signalers could potentially signal maximally in all environmental conditions by using multiple signals, each specialized for a different microhabitat.

Additional support for the efficacy backup hypothesis has been obtained for courtship in wolf spiders. The wolf spider Schizocosa retrorsa, a species with both visual and vibratory courtship signals (Hebets et al. 1996; Hebets and Uetz 1999) can procure just as many copulations in the dark as compared to light conditions, and on granite (which does not transmit vibratory signals) as compared to filter paper (Fig. 2). Use of a multimodal display may allow males to court both during the day and at night, potentially doubling the amount of time during which he can attract a mate. In addition, if a male were to find himself on a substrate that damps the vibratory signals, he could potentially still mate effectively so long as light is available. The use of multiple signals then, specifically in different sensory modalities, could allow a message to be transmitted and received successfully under a variety of environmental conditions. Several other species 


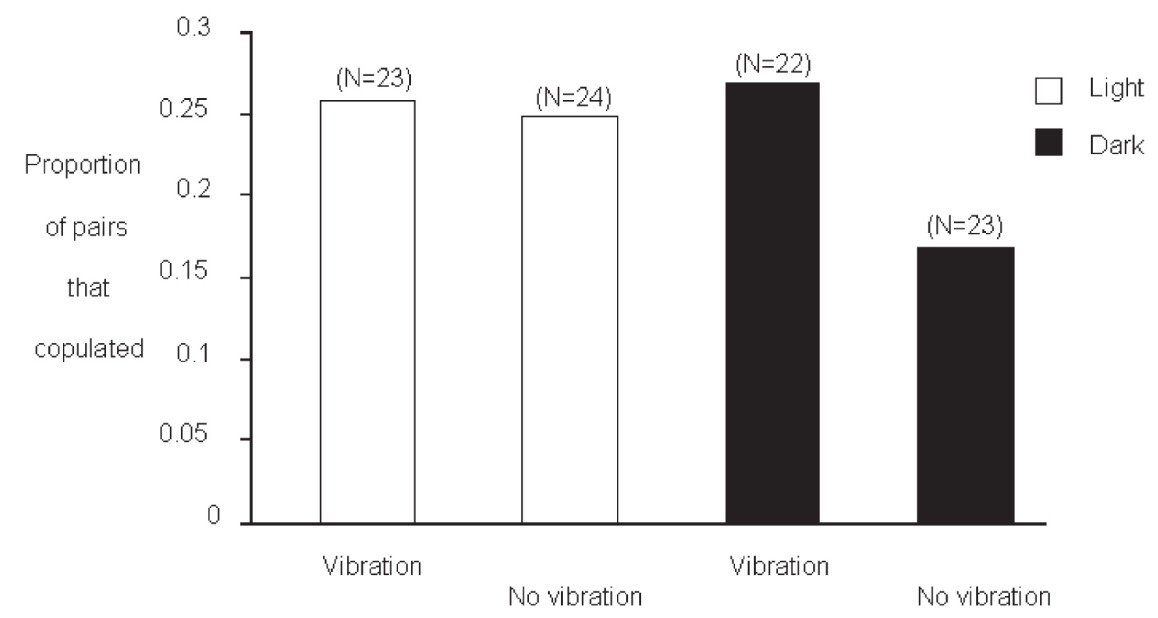

Figure 2. The proportion of pairs of the multimodal signaling wolf spider Schizocosa retrorsa that successfully copulated in environments consisting of independent manipulations of the visual environments (light vs dark : visual signal present vs absent) and vibratory environment (granite substratum vs filter paper : vibratory signal present vs absent). Equal proportions of pairs mated under each condition, providing potential support for an efficacy backup hypothesis.

within the wolf spider genus Schizocosa utilize both visual and vibratory signals to varying degrees and future studies within this genus may provide more examples of efficacy-based backup signals (Table 1).

As with the redundant signal hypothesis, an efficacy backup signal hypothesis is based on imperfect information coding (Bradbury and Vehrencamp 1998). However, in this case, imperfect coding relates not to constraints on sender coding but to signal degradation and attenuation as signals travel through the environment. While both the redundant signal and the efficacy backup signal hypotheses propose a benefit to sending redundant information, the underlying reasons are different. The redundant signal hypothesis proposes that additional signals increase the reliability of the message's content while the efficacy backup hypothesis proposes that additional signals increase the probability of receiver response across a variety of environmental conditions.

2. Efficacy trade-off: The essence of the efficacy trade-off hypothesis is that different signals of a complex display convey the same information but solve different problems in signal efficacy. This hypothesis supposes that, in some cases, no single component or signal can maximize efficacy on all counts. One component might maximize communication range, whereas another may be easiest to localize, while yet another may be processed most effectively, once received.

Clear examples of trade-offs involving communication range and localization exist in many courtship communication systems. In a recent study examining the function of vocal sac movements in túngara frogs (Physalaemus pustulosus), results of a video playback experiment suggest that the visual signal presented by the vocal sac inflation facilitates localization of a calling male in a group of chorusing males (Rosenthal et al. 2004). While the acousti- cal signal is detectable over greater distances than the visual signal, the visual signal is more localizable than the acoustical signal.

In the Mediterranean fruit fly, males in leks release a long-distance pheromone; once females arrive, visual and acoustic signals facilitate localization and mediate female choice. In fireflies, Pleotomus pallens, females produce a pheromone that is used as a long-range attractant and simultaneously emit a photic signal (a glow) that directs males to the specific location of the female (Lloyd 1971).

\section{Sensory constraints}

While the multiple sensory environments category of hypotheses addresses how the environment influences signal transmission and reception, the "sensory constraints" category of hypotheses relates to how the receivers detect and process signals. We outline four hypotheses encompassed by the efficacy-based sensory constraints category of complex signal function: (1) a "parallel processing" hypothesis states that multiple bits of information can be processed simultaneously, potentially reducing the latency to receiver response, (2) a "sensory bias for multisensory integration" hypothesis states that given the existence of multisensory neurons, a multimodal signal enhances the neuronal response, thereby increasing the salience of the event, (3) a "sensory overload" hypothesis states that a signaler can "jam" a receiver's reception and/or processing system by providing more information than can be handled by the receiver's sensory system, and (4) a "perceptual variability" hypothesis states that each signal acts as a backup to the other in the presence of perceptual variability among receivers.

1. Parallel processing: The parallel processing hypothesis states that multiple bits of information can be processed simultaneously, thus reducing the latency 
to receiver response by using independent processing pathways. In the field of neurobiology, parallel processing is presented as one potential solution to problems associated with spike-train variability (Ronacher and Rudiger 2000). Parallel processing is known to be important in different neuronal evaluating processes, for example, in the grasshopper Chorthippus biguttulus, directional hearing and pattern recognition involve parallel processing of the same input functions (Von Helversen 1984). While long temporal processing can also help overcome spike train variability, in a recent study on C. biguttulus, individuals were shown to be able to extract the necessary information for directionality and pattern recognition from a greatly shortened signal $(250 \mathrm{~ms})$, and the authors suggest that these grasshoppers relinquished the benefits of long temporal integration in lieu of parallel processing (Ronacher and Rudiger 2000). Here, we suggest that time benefits of processing various components of a display in parallel may promote the evolution of complex signals.

2. Sensory bias for multisensory integration: The multisensory integration hypothesis states that given the existence of multisensory neurons in animal systems, a multimodal signal enhances the multisensory neuronal response, thereby increasing the salience of the event. While systems exist in which individual sensory modalities are received and processed separately, there also exist multisensory neurons, which pool information from multiple sensory modalities. In the cat, for example, visual, auditory, and somatosensory inputs converge onto multisensory neurons and in a study assessing the spatial determinants of multisensory integration, it was found that the average receptive-field overlap for visual-auditory neurons was 85\% (Meredith and Stein 1996). In this study, when a combined-modality stimulus was used, the multisensory response was enhanced on average $148 \%$ in $87 \%$ of the trials, suggesting that combined stimuli presumably coming from the same event integrate to increase the salience of that event (Meredith and Stein 1996). This enhanced neural response represents another potential function of complex signaling. While this hypothesis requires direct neurophysiological tests, it also requires an evolutionary framework. As stated, this hypothesis assumes that multisensory neurons came first, presumably selected for via natural selection. In essence, this is a sensory bias hypothesis of complex signal evolution and must be tested with regards to phylogenetic relationships.

3. Sensory overload: The sensory overload hypothesis states that a signaler can jam a receiver's reception and/or processing system by providing more information than can be handled by the receiver's sensory system. This hypothesis is most easily thought of in terms of mate choice and sexual conflict (Holland and Rice 1998). Until now, most hypotheses discussed have assumed that signals have, in part, evolved to improve a receiver's capacity to detect and process a signal. If one accepts that signaling strategies do not necessarily benefit a receiver, the possibility arises that complex signals are employed not to relax constraints on information flow, but rather to exploit them (Holland and Rice 1998). For example, complex signals may potentially be used to overwhelm a receiver's ability to process information. If a desired response on the part of the signaler is no overt response at all, then use of multiple signals across sensory modalities may obstruct a receiver's capacity to process information, inhibiting a behavioral response. In some cannibalistic animals, a male's behavior in courtship seems designed in part to prevent a female from killing and eating him, in other words, to inhibit a behavioral response. In some spiders, for example, a male mounts only when a female assumes a sedentary position (Hebets, personal observation). Such a position may constitute a "freeze" response that males achieve by overwhelming a female's capacity to process stimuli and take decisive action. If true, we would expect that during the time that a multimodal signal is being received, receivers should not respond to other stimuli occurring in the same sensory modalities. Isolated components of the complex signal, in contrast, should not reduce responsiveness, or at least not to the same degree.

4. Perceptual variability: The perceptual variability hypothesis states that each signal backs the other up in the presence of perceptual variability among receivers. This hypothesis proposes that parts of the complex signal differ in terms of their capacity to be detected and processed by one receiver versus another. In humans, it is well known that individuals vary in their ability to detect stimuli in various modalities. Individuals vary in visual acuity, with some requiring corrective lenses as a visual aid. Other individuals have good visual acuity at least while young, but have difficulty hearing and may even rely on hearing aids. It is not unreasonable to suppose that individuals in nonhuman species also vary in sensory competence. If so, multimodal signaling, in which the same message is sent in different modalities, could permit signalers to reach a broader audience.

In comparison to the efficacy backup hypothesis, it is not the external environment that influences signal efficacy under the perceptual variability hypothesis, but rather the receiver's internal milieu. Such receiver variability may extend beyond the level of sensory detection to any internal process that affects the efficacy of a receiver's response. If receivers vary in their capacity to process information in various modalities, then multimodal signaling would again permit signalers to reach a broader audience. The receiver variability hypothesis (see above) proposed that complex signals are designed to send different messages to different types of receivers. The per- 
ceptual variability hypothesis also proposes that different components of a complex signal are aimed at different receivers, however, in the latter instance; components of the complex signal differ not in terms of information content but in terms of their capacity to be detected and processed by one receiver versus others.

In a recent review of spike trains and the processing of temporal patterns of acoustic signals, Ronacher et al. (2004) discusses variations in receiver properties (Ronacher et al. 2004). In one grasshopper study females showed significant variation in response to changes in the onset and offset of male songs. One group of females did not respond to models with a small offset but increased their response by $40 \%$ if the offset was increased, while another set of females responded strongly to the model with the small offset (Balakrishnan et al. 2001). Balakrishnan et al. suggest that the variability seen in responses between the groups of females is due to differences among females at the neural level (Balakrishnan et al. 2001).

Several other studies exist that have shown intraspecific variation in sensory sensitivity (Jacobs et al. 1993; McDonald and Hawryshyn 1995). This variation may reflect not only genetically based variation (Endler et al. 2001) but also ontogentically based variation. Receivers vary in age, internal state and recent experience, all of which may affect their competence to process information (Reid and Weatherhead 1990; Grahn and Vonschantz 1994; Gong and Gibson 1996; Marchetti 1998; Hebets 2003).

\section{Inter-signal interaction hypotheses}

Our discussions of how content and efficacy-based selection pressures influence complex signal evolution have thus far assumed that one component or signal of a complex display is independent of the others, meaning that each signal does not alter the production, transmission, reception or processing of another signal. However, it is unlikely that signals within a complex display always act independently. In the remainder of this review, we address what we feel to be the most intriguing category of complex signaling hypotheses: hypotheses derived from inter-signal interactions.

In most instances, an inter-signal interaction occurs when the presence of one signal or component alters the receiver's response to a second signal or component. This could be a change in the probability of response, the timing of response, or the degree of response. In other instances, signals can interact in such a way as to produce an entirely new response, a phenomenon termed "emergence" by Partan and Marler (1999). Inter-signal interaction hypotheses can reflect both content-based and efficacy-based selection pressures, although the latter may be more common (Table 4).

Male satin bowerbirds, $P$. violaceus, provide a good example of interacting male display traits. Male satin bowerbirds have courtship displays that consist of physical traits such as bower quality and decoration as well as behavioral traits such as intensity of courtship displays.
While females prefer males that display intensely (Borgia and Presgraves 1998; Patricelli et al. 2002; Patricelli et al. 2003), displays that are too intense are likely to repel females (Patricelli et al. 2002). Patricelli et al. (2003) recently demonstrated that the presence of decorations at a bower can reduce the female's perceived threat level from a courting male, allowing a male to increase his courtship intensity. In other words, the physical display traits (bower decorations) seem to facilitate the expression of more intense-and thus more attractive-behavioral displays by increasing female "comfort" in early courtships. This system provides an example of inter-signal interactions in which one signal facilitates the other. Candolin (2003) provides an excellent review of other recent studies showing inter-signal interactions in courtship displays. Below we outline four main categories of hypotheses relating to inter-signal interactions.

Our first category of inter-signal interaction hypotheses is "multitasking." A multitasking hypothesis states that a signaler's ability to generate one signal is constrained by its ability to generate a second signal, making generation of both signals difficult and therefore potentially useful in assessing signaler quality. Our second category of inter-signal interaction hypotheses is "increased detection and discrimination." Within this category, the presence of one signal either increases the probability and/or speed of detection of a second signal, or increases the accuracy with which the receiver responds to a second signal. Our third category is "increased learning and memory," in which the presence of one signal increases the ability to learn and/or remember another signal, or the entire display complex. And, the fourth category, labeled "increased deception," states that the accuracy of receiver response is decreased by a complex signal, as compared to the response to either signal in isolation.

\section{Multitasking}

The multitasking hypothesis states that a signaler's ability to generate one signal is constrained by, and thus negatively correlated with, his/her ability to generate another signal. This interaction where the production of one signal interferes with the production of a second makes the generation of both signals difficult and thus potentially informative about signaler quality. This hypothesis suggests that complex signaling is itself an indication of signaler fitness. Under this hypothesis, component signals are predicted to have a tight covariance, but unlike the redundant signal hypothesis, the covariance should be negative.

Signals are typically costly and difficult to produce (Hasson 1994), and multiple signals are presumably even more costly than are single signals. Additionally, the production of signals or signal components may trade off against each other, making the successful combination even more difficult to produce. For example, male brownheaded cowbirds appear to synchronize their most elaborate visual components of their display with long periods 
of silence due to adverse biomechanical effects of movement on song production (Cooper and Goller 2004).

The best example of a signal production trade-off has been demonstrated for trill rate and frequency bandwidth in bird songs. The broader the frequency bandwidth of a song, the slower the trills produced at that bandwidth (Podos 1997). This trade-off may have a significant impact on the attractiveness of a male's song. When a tradeoff between syllable rate and frequency bandwidth was circumvented by synthesizing songs artificially, females significantly preferred playbacks in which there was an exaggerated combination of syllable rate and large bandwidth (Draganoiu et al. 2002). Draganoiu et al. (2002) argued that females are more attracted to these calls because a male that can simultaneously produce high trill rates and a large bandwidth must be a highly fit male. This idea falls in line with the reliable indicator hypothesis (Zahavi 1975). Signalers that can perform multiple tasks simultaneously, especially if they are unusually difficult to do simultaneously (like patting your head with one hand and rubbing your belly with the other, or walking and chewing gum at the same time), and that can perform them well, conceivably represent higher quality individuals. Their concurrent signaling may indicate a general ability to multi-task, and it is intuitively appealing to think that multi-tasking has fitness value. It is also exciting to think about the possibility of overcoming the problems associated with multitasking by coordinating one's activity with another, as is seen in the male coordinated complex displays of long-tailed manakins.

\section{Increased detection and discrimination}

This category of hypotheses states that the presence of one signal either increases the probability and/or speed of detection of a second signal (increased detection), or increases the accuracy with which the receiver responds to a second signal (increased discrimination). The detectability of a signal refers to the ease with which the signal can be detected against its background (Guilford and Dawkins 1991), while the discriminability of a signal refers to the ease with which subtleties of a signal are distinguished. Several efficacy-based hypotheses discussed above dealt with selection for increased signal detection (i.e., "backup signals," "efficacy trade-offs"). Here we explore the possibility that signal detection and discrimination are consequences of inter-signal interactions. While this general category of hypotheses was referred to by Candolin (2003) as "amplifiers" (see also Hasson 1991), we suggest that amplifiers are just one way in which signals can interact to increase detection and discrimination and thus, we distinguish five hypotheses within this general category: (1) an "amplifier" hypothesis states that one signal increases the probability of detection of another signal and/or decreases the detection threshold (i.e., increases conspicuousness), (2) an "alerting and attention-altering" hypothesis states that one signal either alerts a receiver to the presence of another signal, thereby decreasing the re- ceiver's reaction time and/or increasing the probability of receiver response, or influences the information filtering mechanism of the receiver such that the receiver's attention is focused on another signal, (3) a "context" hypothesis states that the presence of one signal provides a context which allows for the receiver to accurately interpret another signal, and (4) an "emergence" hypothesis states that discrimination is increased through the combination of signals which generate entirely new, unique signals.

1. Amplifier: An amplifier hypothesis states that one signal increases the probability of detection and/or discrimination of a second signal, essentially making it more conspicuous. It has been well established that some signals act as amplifiers without conveying additional information (Hasson 1991). Visual ornaments are often added to moving parts in order to make the movements more detectable. For instance, male anolis lizards signal by raising and lowering a brightly colored dewlap in a variety of signaling contexts. Fleishman (2000) demonstrated that the bright colors of the dewlap increase a receiver's detection of the movement (Fleishman 2000). Similarly in Schizocosa wolf spiders, ornamentation found on the forelegs of males of certain species has been proposed to increase the effectiveness of the leg waving display in eliciting female receptivity (Hebets and Uetz 2000). The addition of visual ornaments such as black pigmentation or brushes does not increase receiver response in species that lack movement; however, when visual ornaments are added to males in species that possess a leg waving display, female receptivity is increased markedly (Hebets and Uetz 2000). The amplifier hypothesis predicts a change in the receiver's reception or decision threshold, not simply a warning of another signal to come.

2. Alerting and attention-altering: An alerting hypothesis states that one signal alerts a receiver to the presence of a second signal, thereby decreasing the receiver's reaction time and/or increasing the probability of receiver response. This alerting function may involve sensory priming or simply altered orientation and typically relies on a sequential perception of a complex display. An alerting signal is generally easily detected against the background. The multimodal nuptial signals of male sticklebacks $(\mathrm{Cu}-$ laea inconstans and Gasterosteus aculeatus) are argued to provide examples of a multimodal alerting function. Female sticklebacks are alerted to the presence of a male by an olfactory signal before he can be seen, which presumably increases the detectability of the visual signal (McLennan 2003). While this study only explored female responses to isolated olfactory signals, in order to test an alerting function, one needs to examine the probability of, and latency to, a receiver response to a subsequent signal both in the presence and absence of the putative alerting sig- 
nal. Furthermore, in this example, as the olfactory signal has a greater signal range, this multimodal signal may also function to overcome the efficacy trade-off of range and localization.

An attention-altering hypothesis suggests that the presence of one signal influences the information filtering mechanism of the receiver such that the receiver's attention is focused on another signal. Here, attention refers to all the information that a receiver processes at any given time (Dukas 2002). Since organisms are regularly faced with the possible perception of more stimuli than can be processed at once, they must filter out information and focus attention on what seems pertinent at the time; this process is called selective attention. Examples of attention-altering stimuli are becoming more and more common, especially in studies of primates. It has long been known that the addition of visual cues significantly improves comprehension of auditory cues (Sumby and Pollack 1954). Recent human studies have now also shown that tactile stimulation can enhance visual cortex activity (Macaluso et al. 2000). And visual discrimination has been shown to improve in the presence of tactile stimulation (Spence et al. 1998). These studies, and others, suggest that one signal can increase the degree to which a receiver focuses attention on another sensory field, and by doing so, improves discrimination within that field.

Features of a male wolf spider display, S. uetzi, are also suggestive of an attention-focusing mechanism. In assessing female receptivity responses to video playbacks in which the male foreleg morphology was manipulated into three phenotypes, S. uetzi female receptivity was found to be independent of the video stimuli (Hebets and Uetz 2000). In a second study, however, females were shown these same video sequences simultaneous with the presence of a live male courtship vibration. In the presence of the courtship vibration, females were more receptive to video playbacks of more ornamented males (Hebets 2004), suggesting that the presence of a courtship vibration potentially increases a female's visual attention. A follow-up study revealed that the vibratory courtship signal of a male also causes females to be more susceptible to a visual threat from above (Hebets 2004). The increased vulnerability likely results from the attentionaltering influence of the vibratory signal: vibratory courtship signals cause females to focus their visual attention either forward, or specifically on the image of a courting male (Hebets 2004).

While we combine alerting and attention-altering into one category in this review, we do feel that there are subtle differences. An alerting function predicts variation in probability of and/or latency to receiver response in the presence versus absence of an alerting signal. An attention-altering function, however, predicts variation in the accuracy with which a receiver assesses a signal in the presence versus absence of an attention-altering signal. One hypothesis suggests constraints imposed by the transmission environment and peripheral sensory struc- tures of the receiver (alerting) while the other suggests constraints imposed by the psychology of the receiver and processing capabilities (attention-altering) (Guilford and Dawkins 1991).

3. Context: A context hypothesis states that the presence of one signal provides a context in which a receiver can interpret and respond to a second signal. It has long been understood that a receiver's response to a single signal is often context-dependent (Smith 1965), and this should be no less true for complex signals. The role of one signal in a complex display may be to simply provide a context in which another signal can be interpreted. A possible example of this is provided by the interaction between signals in snapping shrimp, Alpheus heterochaelis. Produced by both sexes, a visually based "open chela" signal elicits different responses depending on the sex of the signaler (Hughes 1996). Males showed a greater response to the visual open chela display in the presence of a chemical signal from a male versus a female, suggesting that the chemical signal modified a male's response to the visual signal. Male response depended on chela size (the visual signal) when presented with a female's chemical signal but not when presented with a male's chemical signal, further suggesting that the response to the visual signal depends on the chemical signal (Hughes 1996). In short, in this system, the chemical signal seems to provide information about the signaler's sex, information that is key to the interpretation of the visual signal.

Several recent studies using chicks (G. gallus domesticus) have also demonstrated an interaction between the odor pyrazine and color aversion, suggesting an increased discrimination function. In the absence of pyrazine, chicks show no discrimination among colors and only in the presence of pyrazine do they show an aversion to yellow and red but not to green or purple (Rowe and Guilford 1996; Rowe and Guilford 1999b). Thus, an unlearned aversion to an aposematic display is observed only in the presence of a particular odor. Another experiment using chicks also demonstrated an interaction between the presence of odors (pyrazines and almond) and an ingestible visual stimulus (food and water). The interaction was observed in the latency to eat or drink. In the presence of pyrazines and almond odors, chicks took longer to eat or drink, but this increased latency was only observed when the ingestible stimulus was novel-colored (Marples and Roper 1996). These results suggest an interaction in which the presence of an odor enhances a chick's neophobia, or unlearned aversion (Marples and Roper 1996). The mechanism underlying this unlearned discrimination and enhanced neophibia is currently unknown, but it is possible that the odor provides a context in which to assess color.

4. Emergence: An emergence hypothesis states that a receiver is better able to discriminate among signalers due to the emergent properties of combining multi- 
ple signals in such a way that a new, unique signal is formed. In this instance, one signal does not increase the discriminability of a second, but instead, both signals combined create a novel signal that can potentially vary among individuals. The various ways in which multiple components might combine allows for a potentially large repertoire of complex signals. The need for many unique signals may be of particular importance where individual recognition is favored, for example, in many social systems. In a recent study examining the variable facial and abdominal markings of Polistes fuscatus wasps, Tibbetts (2002) demonstrated that combinations of these markings mediated individual recognition. Individual recognition, achieved through complex signaling, is important in establishing and maintaining the dominancy hierarchy within the nest (Tibbetts 2002).

\section{Increased learning and memory}

The category of hypotheses involving increased learning and memory represents instances where the presence of one signal increases a receiver's ability to learn and/or remember another signal or the entire display. While it is clear that the ability of a receiver to learn and remember a complex signal can be affected by inter-signal interactions, the underlying mechanism is not known. Thus, we do not distinguish any specific hypotheses within this more general category.

Examples of inter-signal interactions increasing learning and memory are few, but are becoming more prevalent as interest in the field increases. Rats (Rattus norvegicus) have been shown to learn to avoid distasteful water more quickly when a pyrazine odor is present versus absent (Kaye et al. 1989). Domestic chicks (G. gallus domesticus) enhanced their rate of learning to avoid distasteful water of a familiar color in the presence of a novel odor (Roper and Marples 1997). Sound has also been shown to interact with visual stimuli in domestic chicks. Rowe (2002) trained chicks to find food that was hidden underneath hats of two different colors (green and purple), either in the presence or absence of a sound. The presence of sound significantly increased the speed with which the chicks learned to avoid unrewarding hats (Rowe 2002). It seems likely that complex signaling may be relevant in the efficacy of imprinting as well. While relatively few studies have examined the role of inter-signal interactions in learning and memory in nonhuman animals, the prominence of this role in human communication (reviewed in Rowe 1999) suggests that when we look more closely, nonhuman examples may be common.

\section{Increased deception}

The increased deception category of hypotheses states that the presence of one signal decreases the accuracy with which a receiver responds to another signal. Signal- ers may not always endeavor to increase detection, discrimination and memory, but instead to reduce them. Particular combinations of signals or components can create illusions that deceive the eye, or other sensory devices, and thus convey inaccurate information to a receiver in a way that benefits a signaler. For example, interactions between motion and color against a natural background have been shown to alter a predator's ability to detect and successfully attack prey. By using complex anti-predator signals, individuals can increase the probability of their escape. The interaction of particular striped patterns, for example, with directed motion can deceive a predator as to the prey's true velocity (Jackson et al. 1976; Brodie 1992). Predators confronted with a complex signal selected for increased deception would be more likely to make mistakes in calculating distance/direction/or speed of prey when presented with an entire complex signal as compared to when certain components or signals are removed.

\section{Practical approaches to assessing complex signal function}

Thus far, we have outlined general categories of complex signal function, provided examples where possible, and attempted to highlight key predictions for the hypotheses presented. Another goal of this review was to provide a platform from which future researchers can launch explorations of new systems and new taxa. One major pattern that emerged from compiling the studies cited in this manuscript is that researchers use two distinct approaches in exploring complex signal function: (1) a signal(er)-based approach and (2) a receiver-based approach. While both approaches are certainly valid, depending on the taxon in question, the amount and type of background information available, and the intuition of the researcher, one approach may initially make more sense than another. In the end, a full understanding of the topic of complex signaling will require both approaches.

In studying complex signaling, we recommend that four key questions (not in any particular order) be addressed: (1) Do the signals covary and if so, is it a positive or a negative covariance? (2) Do any/all of the signals covary with signaler quality? (3) Are the signals necessary and/or sufficient to elicit a receiver response? (4) Does the presence of one signal influence the receiver's response to a second? Answering these questions for any given system should permit one to narrow down the possible hypotheses relating to the function of a complex display.

\section{Discussion}

Throughout our review, we have attempted to make three points:

1. Complex signals form functional units upon which selection acts. 
2. Both content-based and efficacy-based selection pressures may account for complex signal function.

3. Individual components of complex signals need not be independent, but can interact in a functional way.

Our overall goal with this review is to provide a workable framework of hypotheses relating to complex signal function, using key examples where applicable. Our hope is that this framework will help to guide studies of complex signaling and to provide a foundation upon which future studies can build.

How much work lies ahead of us in the area of complex signaling is perhaps best illustrated by an example involving honeybee waggle dance communication, one of the classic case studies in animal communication. Despite intense study of this communication system over a period of 50 years, questions still remain regarding how information about the distance and direction of floral resources is transferred from dancer to follower bees and even less about how candidate signals in the dance are integrated to convey that information (Dyer 2002). In Apis mellifera, three sensory modalities have been implicated as vehicles of spatial information about floral resources: airborne sounds of ca. $250 \mathrm{~Hz}$ produced by the dancers' wings, substrate-borne vibrations of $10-15 \mathrm{~Hz}$ produced by the dancers body movements, and tactile stimuli. It is conceivable that each putative signal encodes distance and directional information conveyed by the dance. If so, the multimodal nature of the dance might function to confirm information (redundant signal hypothesis). Alternatively, the various signals might back each other up in a noisy and variable social environment (efficacy backup hypothesis). Or, given that substrate-borne vibrations may be more detectable farther from the dancer than are the near-field sounds, and may be more accessible than tactile signals to more bees, use of multiple signals might reflect some kind of trade-off between signal range and reliability (efficacy trade-off hypothesis). Unfortunately, not only do we not have evidence bearing on these various hypotheses, we are not yet certain to what extent each component encodes distance and/or direction. For instance, while sound potentially conveys both distance and directional information, experiments to date do not rule out the possibility that the sound simply attracts follower bees to a dancer, but is not itself the modality conveying spatial information (Dyer 2002). Such an interpretation suggests yet a fourth hypothesis, namely that the dancers sounds improve the efficacy of the signal conveying spatial information (cf. increased detection hypothesis).

Providing further documentation for the functional basis of complex signals will be challenging for a variety of reasons. First, as illustrated by the example of the waggle dance, the hypotheses put forward in this review are generally not mutually exclusive and, in many cases, more than one hypothesis may account for complex signal function. Second, it is possible that some complex signals may not be functional units, but might only appear to be (i.e., signals may be emitted coincident in time and space but may otherwise be independent). Moreover, complex displays may not always be synchronized in time. The issue of sequential versus simultaneous signaling is extremely important, albeit beyond the scope of the present review. Third, distinguishing among hypotheses can be extremely challenging since the various approaches to unraveling the function of complex signals are vastly different in terms of techniques and terminology. Ultimately, one needs to incorporate both signal(er)-based and receiver-based approaches to testing hypotheses in order to understand the function of any complex signal fully. Fourth, the predictions and tests of all hypotheses become yet more complicated by the fact that complex signals may consist of more than two parts. As the number of modalities and signals/components increases, so does the difficulty in testing predictions and distinguishing between alternative explanations.

Critical to all of these issues is an experimental approach in which components of a complex signal are manipulated and receiver responses to isolated versus combined components are assayed. It has not always been easy to decompose a complex signal in order to evaluate its components and a possible interaction among them. In this regard, recent advances in video technology and robotics will greatly facilitate the analysis of complex signals.

Finally, we focused throughout this review almost exclusively on the benefits that complex signals provide to the signaler and sometimes to the receiver. However, we know that signals are often costly (Hasson 1994). Given that signals are costly, in order for complex signaling to evolve, the benefits of such signaling must outweigh the costs. The added costs of complex signaling that we envision signalers having to overcome include: added energy expenditure, increased conspicuousness to potential predators, and added avenues for eavesdropping or aggressive mimicry. While our goal here was not to implement general theories of signaling that make a complete accounting of benefits and costs, such an accounting must ultimately be made if we are to fully understand the form and distribution of complex signaling in nature.

\section{Acknowledgments}

We would like to thank R. Hoy, K. Reeve, J. Bradbury, N. Vander Sal, D. Elias, and members of the Papaj Lab for commenting on earlier drafts of this manuscript. We would also like to thank A. Cutter and W. Maddison for fruitful discussions and two anonymous reviewers for invaluable suggestions and insights.

\section{References}

Acquistapace P, Aquiloni L, Hazlett BA, Gherardi F (2002) Multimodal communication in crayfish: sex recognition during mate search by male Austropotamobius pallipes. Can J Zool 80:2041-2045

Andersson M (1982) Female choice selects for extreme tail length in a Widowbird. Nature 299:818-820 
Badyaev AV, Hill GE (2000) Evolution of sexual dichromatism: contribution of carotenoid- versus melanin-based coloration. Biol J Linn Soc 69:153-172

Bailey WJ (1991) Acoustic behaviour of insects: an evolutionary perspective. Chapman and Hall, London

Bailey WJ, Cunningham RJ, Lebel L (1990) Song power, spectral distribution and female phonotaxis in the bushcricket Requena-Verticalis (Tettigoniidae, Orthoptera)-active female choice or passive attraction. Anim Behav 40:33-42

Balakrishnan R, Helversen D von, Helversen O von (2001) Song pattern recognition in the grasshopper Chorthippus biguttulus: the mechanism of syllable onset and offset detection. J Comp Physiol A 187:255-264

Basolo AL (1990) Female preference predates the evolution of the sword in swordtail fish. Science 250:808-810

Baurecht D, Barth FG (1992) Vibratory communication in spiders .1. Representation of male courtship signals by female vibration receptor. J Comp Physiol A 171:231-243

Birkhead TR, Fletcher F, Pellatt EJ (1998) Sexual selection in the zebra finch Taeniopygia guttata: condition, sex traits and immune capacity. Behav Ecol Sociobiol 44:179-191

Bischoff RJ, Gould JL, Rubenstein DI (1985) Tail size and female choice in the guppy (Poecilia reticulata). Behav Ecol Sociobiol 17:253-255

Blanco G, De la Puente J (2002) Multiple elements of the blackbilled magpie's tail correlate with variable honest information on quality in different age/sex classes. Anim Behav 63:217-225

Borgia G, Presgraves DC (1998) Coevolution of elaborated male display traits in the spotted bowerbird: an experimental test of the threat reduction hypothesis. Anim Behav 56:1121-1128

Bradbury JW, Vehrencamp SL (1998) Principles of animal communication. Sinauer, Sunderland, Mass.

Brodie ED (1992) Correlational selection for color pattern and antipredator behavior in the garter snake Thamnophis ordinoides. Evolution 46:1284-1298

Brooks R, Caithness N (1995) Does a males attractiveness to a female depend on her previous experience. S Afr J Sci 91:156-158

Buchholz R (1991) Older males have bigger knobs-Correlates of ornamentation in 2 species of curassow. Auk 108:153-160

Candolin U (2003) The use of multiple cues in mate choice. Biol Rev 78:575-595

Candolin U, Reynolds JD (2001) Sexual signaling in the European bitterling: females learn the truth by direct inspection of the resource. Behav Ecol 12:407-411

Coleman SW, Patricelli GL, Borgia G (2004) Variable female preferences drive complex male displays. Nature 428:742-745

Cooper BG, Goller F (2004) Multimodal signals: enhancement and constraint of song motor patterns by visual display. Science 303:544-546

Cott HB (1940) Adaptive coloration in animals. Methuen, London

Cynx J, Lewis R, Tavel B, Tse H (1998) Amplitude regulation of vocalizations in noise by a songbird, Taeniopygia guttata. Anim Behav 56:107-113

De caprona MDC, Ryan MJ (1990) Conspecific mate recognition in swordtails, Xiphophorus nigrensis and X. pygmaeus (Poeciliidae) - Olfactory and visual cues. Anim Behav 39:290-296

Doucet SM, Montgomerie R (2003) Multiple sexual ornaments in satin bowerbirds: ultraviolet plumage and bowers signal different aspects of quality. Behav Ecol 14:503-509

Draganoiu TI, Nagle L, Kreutzer M (2002) Directional female preference for an exaggerated male trait in canary (Serinus canaria) song. Proc R Soc Lond B Biol Sci 269:2525-2531

Dukas R (2002) Behavioural and ecological consequences of limited attention. Philos Trans R Soc Lond B Biol Sci 357:1539-1547

Dyer FC (2002) The biology of the dance language. Annu Rev Entomol 47:917-949

Edmunds M (1974) Defense in animals. Longman, Harlow

Endler JA (1992) Signals, signal conditions, and the direction of evolution. Am Nat 139:S125-S153

Endler JA, Thery M (1996) Interacting effects of lek placement, display behavior, ambient light, and color patterns in three neotropical forest-dwelling birds. Am Nat 148:421-452

Endler JA, Basolo AL, Glowacki S, Zerr J (2001) Variation in response to artificial selection for light sensitivity in guppies (Poecilia reticulata). Am Nat 158:36-48

Ewing A (1989) Arthropod bioacoustics: neurobiology and behavior. Cornell University, Ithaca

Fleishman LJ (2000) Signal function, signal efficiency and the evolution of anoline lizard dewlap color. In: Epsmark Y, Amundsen T GR (eds) Animal Signals: signalling and signal design in animal communication. Tapir Academic, Trondheim, pp 209-236

Fox D (1976) Animal biochromes and structural colors. University of California Press, Berkeley, Calif.

Gerhardt HC (1991) Female mate choice in treefrogs-static and dynamic acoustic criteria. Anim Behav 42:615-635

Gerhardt HC, Huber F (2002) Acoustic communication in insects and anurans. University of Chicago Press, Chicago

Glassey B, Forbes S (2002) Muting individual nestlings reduces parental foraging for the brood. Anim Behav 63:779-786

Gong A, Gibson RM (1996) Reversal of a female preference after visual exposure to a predator in the guppy, Poecilia reticulata. Anim Behav 52:1007-1015

Grahn M, Vonschantz T (1994) Fashion and age in pheasantsage-differences in mate choice. Proc R Soc Lond B Biol Sci 255:237-241

Grether GF (1996) Sexual selection and survival selection on wing coloration and body size in the rubyspot damselfly Hetaerina americana. Evolution 50:1939-1948

Grether GF, Hudon J, Millie DF (1999) Carotenoid limitation of sexual coloration along an environmental gradient in guppies. Proc R Soc Lond B Biol Sci 266:1317-1322

Guilford T, Dawkins MS (1991) Receiver psychology and the evolution of animal signals. Anim Behav 42:1-14

Halliday TR, Slater PJB (1983) Animal behaviour, vol 2. Freeman, New York

Hankison SJ, Morris MR (2002) Sexual selection and species recognition in the pygmy swordtail, Xiphophorus pygmaeus: conflicting preferences. Behav Ecol Sociobiol 51:140-145

Hasson O (1989) Amplifiers and the handicap principle in sexual selection: a different emphasis. Proc R Soc Lond B Biol Sci 235

Hasson O (1991) Sexual displays as amplifiers-practical examples with an emphasis on feather decorations. Behav Ecol 2:189-197

Hasson O (1994) Cheating signals. J Theor Biol 167:223-238 
Hasson O (1997) Towards a general theory of biological signaling. J Theor Biol 185:139-156

Hauser M (1996) The evolution of communication. MIT Press, Cambridge, Mass.

Hebets EA (2002) The evolution and function of complex signaling in spider courtship behavior. Ecology and evolutionary biology. PhD dissertation, University of Arizona, Tucson, Ariz.

Hebets E (2003) Subadult experience influences adult mate choice in an arthropod: exposed female wolf spiders prefer males of a familiar phenotype. Proc Natl Acad Sci USA 100:13390-13395

Hebets EA (2004) Attention-altering interaction in the multimodal courtship display of the wolf spider Schizocosa uetzi. Behav Ecol (in press)

Hebets EA, Uetz GW (1999) Female responses to isolated signals from multimodal male courtship displays in the wolf spider genus Schizocosa (Araneae : Lycosidae). Anim Behav $57: 865-872$

Hebets EA, Uetz GW (2000) Leg ornamentation and the efficacy of courtship display in four species of wolf spider (Araneae : Lycosidae). Behav Ecol Sociobiol 47:280-286

Hebets EA, Stratton GE, Miller GL (1996) Habitat and courtship behavior of the wolf spider Schizocosa retrorsa (Banks) (Araneae, Lycosidae). J Arachnol 24:141-147

Holland B, Rice WR (1998) Perspective: chase-away sexual selection: antagonistic seduction versus resistance. Evolution $52: 1-7$

Hölldobler B (1999) Multimodal signals in ant communication. J Comp Physiol A 184:129-141

Hughes M (1996) The function of concurrent signals: visual and chemical communication in snapping shrimp. Anim Behav 52:247-257

Jackson J, Ingram WI, Campbell HW (1976) The dorsal pigmentation pattern of snakes as an antipredator strategy: a multivariate approach. Am Nat 110:1029-1053

Jacobs GH, Neitz J, Neitz M (1993) Genetic basis of polymorphism in the color vision of platyrrhine monkeys. Vision Res 33:269-274

Jawor JM, Gray N, Beall SM, Breitwisch R (2004) Multiple ornaments correlate with aspects of condition and behaviour in female northern cardinals, Cardinalis cardinalis. Anim Behav 67:875-882

Jetz W, Rowe C, Guilford T (2001) Non-warning odors trigger innate color aversions - as long as they are novel. Behav Ecol 12:134-139

Johnstone RA (1996) Multiple displays in animal communication: 'backup signals' and 'multiple messages'. Philos Trans R Soc Lond B Biol Sci 351:329-338

Kaye H, Mackintosh NJ, Rothschild M (1989) Odour of pyrazine potentiates an association between environmental cues and unpalatable taste. Anim Behav 37:563-568

Leal M, Fleishman LJ (2004) Differences in visual signal design and detectability between allopatric populations of Anolis lizards. Am Nat 163:26-39

Lengagne T, Slater PJB (2002) The effects of rain on acoustic communication: tawny owls have good reason for calling less in wet weather. Proc R Soc Lond B Biol Sci 269:2121-2125

Lengagne T, Aubin T, Lauga J, Jouventin P (1999) How do king penguins (Aptenodytes patagonicus) apply the mathematical theory of information to communicate in windy conditions? Proc R Soc Lond B Biol Sci 266:1623-1628
Ligon JD, Zwartjes PW (1995) Ornate plumage of male red junglefowl does not influence mate choice by females. Anim Behav 49:117-125

Lindstrom L, Rowe C, Guilford T (2001) Pyrazine odour makes visually conspicuous prey aversive. Proc R Soc Lond B Biol Sci 268:159-162

Lloyd JE (1971) Bioluminescent communication in insects. Annu Rev Entomol 16:97-122

Macaluso E, Frith CD, Driver J (2000) Modulation of human visual cortex by crossmodal spatial attention. Science 289:1206-1208

Marchetti K (1998) The evolution of multiple male traits in the yellow-browed leaf warbler. Anim Behav 55:361-376

Markl H (1983) Vibrational communication. In: Huber R, Markl H (eds) Neuroethology and behavioral physiology. Springer, Berlin Heidelberg New York, pp 332-353

Marples NM, Roper TJ (1996) Effects of novel colour and smell on the response of naive chicks towards food and water. Anim Behav 51:1417-1424

Marples NM, Van Veelen W, Brakefield PM (1994) The relative importance of colour, taste and smell in the protection of an aposematic insect Coccinella septempunctata. Anim Behav 48:967-974

Maynard Smith J, Harper DGC (1995) Animal signals: models and terminology. J Theor Biol 177:305-311

McClintock WJ, Uetz GW (1996) Female choice and pre-existing bias: visual cues during courtship in two Schizocosa wolf spiders (Araneae: Lycosidae). Anim Behav 52:167-181

McDonald CG, Hawryshyn CW (1995) Intraspecific variation of spectral sensitivity in threespine stickleback (Gasterosteus aculeatus) from different photic regimes. J Comp Physiol A 176:255-260

McGraw KJ, Hill GE (2000) Differential effects of endoparasitism on the expression of carotenoid- and melanin-based ornamental coloration. Proc R Soc Lond B Biol Sci 267:1525-1531

McLennan DA (2003) The importance of olfactory signals in the gasterosteid mating system: sticklebacks go multimodal. Biol J Linn Soc 80:555-572

Meredith MA, Stein BE (1996) Spatial determinants of multisensory integration in cat superior colliculus neurons. J Neurophysiol 75:1843-1857

Møller AP, Pomiankowski A (1993) Why have birds got multiple sexual ornaments. Behav Ecol Sociobiol 32:167-176

Møller AP, Thornhill R (1998) Bilateral symmetry and sexual selection: a meta-analysis. Am Nat 151:174-192

Narins PM, Capranica RR (1976) Sexual differences in auditory-system of tree frog Eleutherodactylus coqui. Science 192:378-380

Partan S, Marler P (1999) Behavior-communication goes multimodal. Science 283:1272-1273

Patricelli GL, Uy JAC, Walsh G, Borgia G (2002) Male displays adjusted to female's response-macho courtship by the satin bowerbird is tempered to avoid frightening the female. Nature 415:279-280

Patricelli GL, Uy JAC, Borgia G (2003) Multiple male traits interact: attractive bower decorations facilitate attractive behavioural displays in satin bowerbirds. Proc R Soc Lond B Biol Sci 270:2389-2395

Petrie M, Halliday T, Sanders C (1991) Peahens prefer peacocks with elaborate trains. Anim Behav 41:323-331 
Pfennig KS (1998) The evolution of mate choice and the potential for conflict between species and mate-quality recognition. Proc R Soc Lond B Biol Sci 265:1743-1748

Podos J (1997) A performance constraint on the evolution of trilled vocalizations in a songbird family (Passeriformes:Emberizidae). Evolution 51:537-551

Reid ML, Weatherhead PJ (1990) Mate-choice criteria of Ipswich sparrows - the importance of variability. Anim Behav 40:538-544

Ronacher B, Rudiger K (2000) Temporal integration vs. parallel processing: coping with the variability of neuronal messages in directional hearing of insects. Eur J Neurosci 12:2147-2156

Ronacher B, Franz A, Wohlgemuth S, Hennig R (2004) Variability of spike trains and the processing of temporal patterns of acoustic signals-problems, constraints, and solutions. J Comp Physiol A 190:257-277

Roper TJ, Marples NM (1997) Odour and colour as cues for taste-avoidance learning in domestic chicks. Anim Behav 53:1241-1250

Rosenthal GG, Rand AS, Ryan MJ (2004) The vocal sac as a visual cue in anuran communication: an experimental analysis using video playback. Anim Behav 68:55-58

Rothschild M (1961) Defensive odours and Mullerian mimicry among insects. Trans R Entomol Soc Lond 113:101-121

Rothschild M, Haskell PT (1966) Stridulation of the garden tiger moth Arctia caja audible to the human ear. Proc R Entomol Soc Lond A 41:167-170

Rowe C (1999) Receiver psychology and the evolution of multicomponent signals. Anim Behav 58:921-931

Rowe C (2002) Sound improves visual discrimination learning in avian predators. Proc R Soc Lond B Biol Sci 269:1353-1357

Rowe C, Guilford T (1996) Hidden colour aversions in domestic clicks triggered by pyrazine odours of insect warning displays. Nature 383:520-522

Rowe C, Guilford T (1999a) The evolution of multimodal warning displays. Evol Ecol 13:655-671

Rowe C, Guilford T (1999b) Novelty effects in a multimodal warning signal. Anim Behav 57:341-346

Rowe C, Guilford T (2001) The evolution of multimodal warning displays. Evol Ecol 13:655-671

Ryan MJ (1980) Female mate choice in a neotropical frog. Science 209:523-525

Ryan MJ (1985) Energetic efficiency of vocalization by the frog Physalaemus pustulosus. J Exp Biol 116:47-52

Ryan MJ, Rand AS (1990) The sensory basis of sexual selection for complex calls in the Tungara frog, Physalaemus pustulosus (Sexual Selection for Sensory Exploitation). Evolution 44:305-314

Ryan MJ, Wagner WE (1987) Asymmetries in mating preferences between species-female swordtails prefer heterospecific males. Science 236:595-597

Savalli UM (1994) Tail length affects territory ownership in the yellow-shouldered widowbird. Anim Behav 48:105-111

Scheffer SJ, Uetz GW, Stratton GE (1996) Sexual selection, male morphology, and the efficacy of courtship signalling in two wolf spiders (Araneae: Lycosidae). Behav Ecol Sociobiol $38: 17-23$
Scheuber H, Jacot A, Brinkhof MWG (2003a) Condition dependence of a multicomponent sexual signal in the field cricket Gryllus campestris. Anim Behav 65:721-727

Scheuber H, Jacot A, Brinkhof MWG (2003b) The effect of past condition on a multicomponent sexual signal. Proc R Soc Lond B Biol Sci 270:1779-1784

Schuler W, Roper TJ (1992) Responses to warning coloration in avian predators. Adv Stud Behav 21:111-146

Smith C, Reynolds JD, Sutherland W, Jurajda P (2000) Adaptive host choice and avoidance of superparasitism in the spawning decisions of bitterling (Rhodeus sericeus). Behav Ecol Sociobiol 48:29-35

Smith JW (1965) Message, meaning, and context in ethology. Am Nat 97:405-409

Spence C, Nicholls MER, Gillespie N, Driver J (1998) Cross-modal links in exogenous covert spatial orienting between touch, audition, and vision. Percept Psychophys 60:544-557

Stokes D (1979) Stokes nature guides: a guide to bird behavior, vol I. Little, Brown, Boston

Stokes D, Stokes L (1983) Stokes nature guides: a guide to bird behavior, vol II. Little, Brown, Boston

Stokes D, Stokes L (1998) Stokes nature guides: a guide to bird behavior, vol III. Little, Brown, Boston

Sumby WH, Pollack I (1954) Visual contribution to speech intelligibility in noise. J Acoust Soc Am 26:1298-1319

Tibbetts EA (2002) Visual signals of individual identity in the wasp Polistes fuscatus. Proc R Soc Lond B Biol Sci 269:1423-1428

Tregenza T, Wedell N (2000) Genetic compatibility, mate choice and patterns of parentage: invited review. Mol Ecol 9:1013-1027

Uetz GW, Roberts JA (2002) Multisensory cues and multimodal communication in spiders: insights from video/audio playback studies. Brain Behav Evol 59:222-230

Van Staaden MJ, Romer H (1997) Sexual signalling in bladder grasshoppers: tactical design for maximizing calling range. J Exp Biol 200:2597-2608

Von Helversen D (1984) Parallel processing in auditory pattern recognition and directional analysis by the grasshopper Chorthippus biguttulus L. (Acrididae). J Comp Physiol 154:837-846

Wedekind C, Meyer P, Frischknecht M, Niggli UA, Pfander H (1998) Different carotenoids and potential information content of red coloration of male three-spined stickleback. J Chem Ecol 24:787-801

Wells KD (1977) The courtship of frogs. In: Taylor DH, Sheldon IG (eds) The reproductive biology of amphibians. Plenum, New York, pp 233-262

Wiley RH (1994) Errors, exaggeration, and deception in animal communication. In: Real L (ed) Behavioral mechanisms in evolutionary ecology. University of Chicago Press, Chicago

Wilson EO (1975) Sociobiology. The new synthesis. Harvard University Press, Cambridge

Zahavi A (1975) Mate selection-selection for a handicap. J Theor Biol 53:205-214

Zahavi A (1987) The theory of signal selection and some of its implications. In: Delfino V (ed) International symposium of biological evolution. Adriatica Editrice, Bari, pp 305-327

Zuk M, Ligon JD, Thornhill R (1993) Effects of experimental manipulation of male secondary sex characteristics on female mate preference in red jungle fowl. Anim Behav 44:999-1006 